\title{
The problem of large samples: An activation analysis study of electronic waste material
}

\author{
C. Segebade, ${ }^{1 *}$ P. Bode, ${ }^{2}$ W. Goerner ${ }^{1}$ \\ ${ }^{I}$ Federal Institute for Materials Research and Testing (BAM), Berlin, Germany \\ ${ }^{2}$ Interfaculty Reactor Institute (IRI), Delft University of Technology, Delft, The Netherlands
}

(Received April 13, 2006)

\begin{abstract}
Large-volume instrumental photon activation analysis (IPAA) was used for the investigation of shredded electronic waste material. Sample masses from 1 to 150 grams were analyzed to obtain an estimate of the minimum sample size to be taken to achieve a representativeness of the results which is satisfactory for a defined investigation task. Furthermore, the influence of irradiation and measurement parameters upon the quality of the analytical results were studied. Finally, the analytical data obtained from IPAA and instrumental neutron activation analysis (INAA), both carried out in a large-volume mode, were compared. Only parts of the values were found in satisfactory agreement.
\end{abstract}

\section{Introduction}

One of the unwanted consequences of the nowadays large-scale use of high-technology electronic equipment is the dramatic increase of electronic waste with all its implications concerning environmental impact, longterm availability of material and energy resources (Fig. 1). Regarding the respective EU Directives (e.g., WEEE, ${ }^{1}$ RoHS, ${ }^{2}$ Battery Directive $\left.{ }^{3}\right)$ as well as international agreements (e.g., Kyoto Protocol) the electronic waste handling policy will have to be modified radically. Research and development efforts aiming to avoid undesirable landfill/combustion and favouring quasi complete recycling are urgently needed. The first step in this direction is the comprehensive knowledge of the content of components in this waste. These include hazardous ones (arsenic, selenium, cadmium, lead, etc.), usable ones (noble metals, germanium, indium, etc.), those both toxic and usable (nickel, selenium, bromine, etc.) and quasi neutral material (aluminum, iron, zirconium, etc.). Therefore, a new analytical approach for fast characterization of large batches of material at economically acceptable effort is required.

Modern analytical techniques mostly strive to analyze microamounts of sample material and to achieve accordingly high sensitivities of detection. Conversely, to tackle the aforesaid analytical problem, it is frequently necessary to comprise large amounts of analytical material combined with a broad range of detectability so as to analyze both major and minor components with a high degree of accuracy and precision. Furthermore, large samples are more likely to be representative, and thus a respective analytical technique will save time and expenses. Among the vast number of analytical techniques only a few enable the analysis of large masses, respectively, volumes. These are radioactivation techniques in the first instance. In this paper, the application of instrumental large-volume activation analysis using high energy photons (IPAA) and neutrons (INAA) for the analysis of shredded electronic waste is described. For IPAA the large volume irradiation facility (High Energy Photon Screen, HEPS; Fig. 2) of the electron linear accelerator of the Federal Institute for Materials Research and Testing in Berlin, Germany (BAM-LINAC) was used. ${ }^{4-6}$ INAA was carried out at the large volume irradiation facility at the research reactor of the Interfaculty Reactor Institute (IRI), Delft University of Technology, The Netherlands. IPAA was used to explore the limits of detection and analytical precision of the analyses of up to 150 gram, batches of electronic waste. The application to yet larger amounts will be an objective of future studies. The analytical values of a particular batch of electronic waste (shredded TV sets) obtained by both methods were compared.

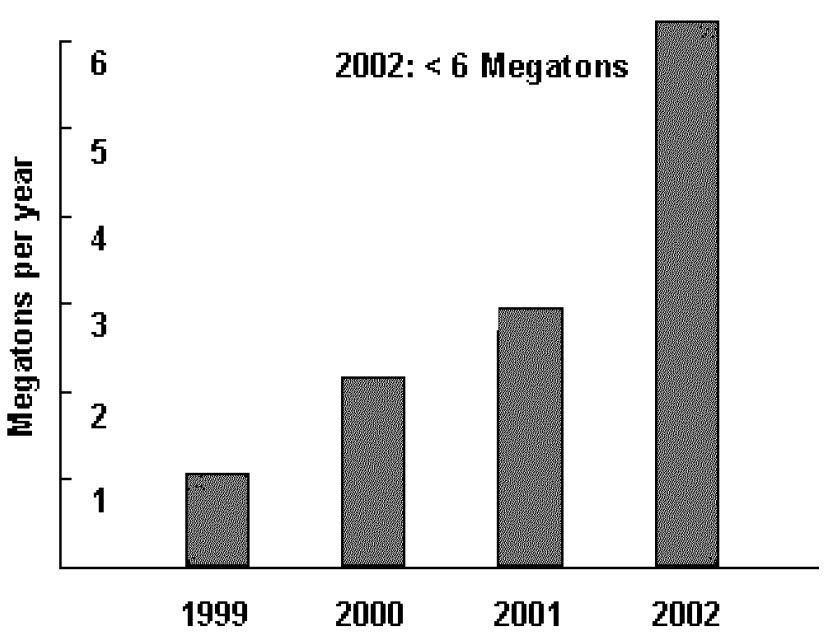

Fig. 1. Annual increase of the amount of electronic waste in the EU 


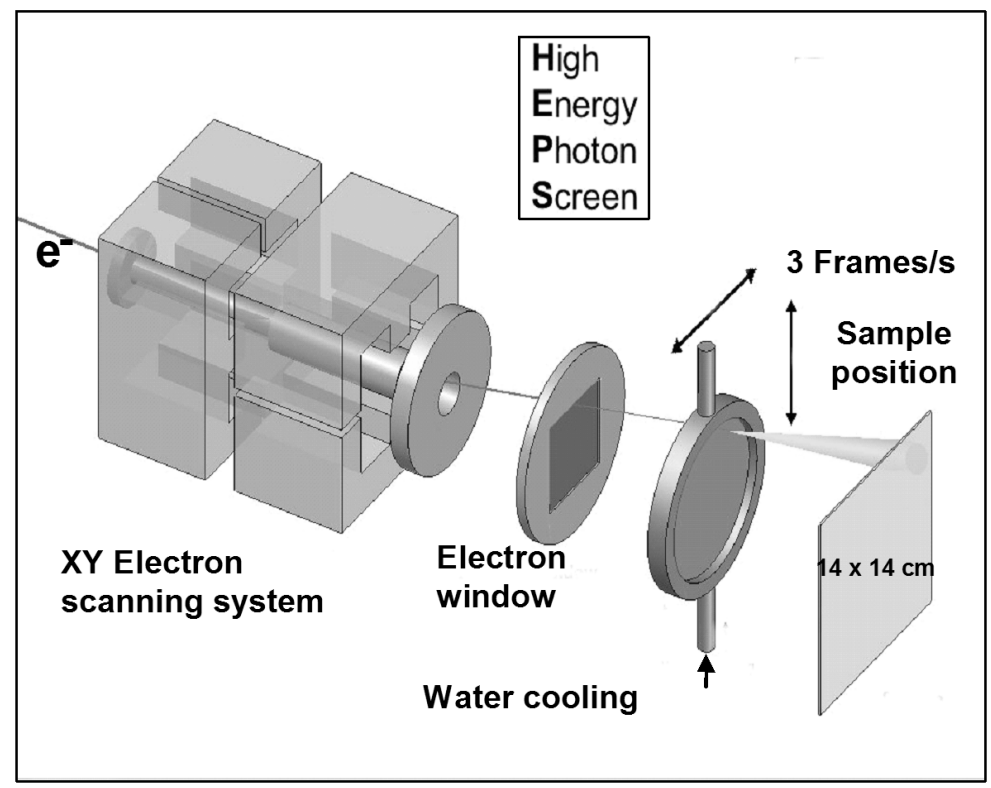

Fig. 2. Scheme of the electron beam scanner of the BAM LINAC

The particular advantages of large volume analysis applied to electronic waste and other material has already been discussed (see, e.g., BODE et al.). ${ }^{7}$

\section{Experimental}

The experimental details of large-sample INAA were discussed by OVERWATER et al. ${ }^{8}$

A major problem in activation analysis of large samples is the inhomogeneity of the activating radiation field. This is true in particular for IPAA. To overcome this problem, the BAM LINAC was equipped with an electron beam scanning system (Fig. 2) with the help of which large volumes can be activated with a good radial field homogeneity. Details of this facility are discussed elsewhere. ${ }^{4,6}$

\section{The material}

The test material was taken from shredded whole TV sets. These had not been dismantled and divided into different components before shredding. Hence, the samples contained material from the housing and the cathode ray tube besides the electronic parts. Sets of five subsamples of respectively 1, 3, 30 and 150 grams were taken for analysis.

\section{Sample preparation for bremsstrahlung exposure}

The samples were filled into flat cylindrical aluminum containers of different sizes (maximum: $8 \mathrm{~cm}$ diameter and $1.6 \mathrm{~cm}$ thickness for the $150 \mathrm{~g}$ - batches) according to the different sample masses. Discs from copper sheet of $25 \mu \mathrm{m}$ thickness and diameters congruent to the respective sample containers were fixed to the front and rear side of those (Fig. 3). The copper discs served as flux monitors to account for the downstream photon flux gradient. ${ }^{4}$ The sample stack was then brought before the tantalum bremsstrahlung converter target of the LINAC (Fig. 3).

\section{Bremsstrahlung exposure}

During activation it was strived to provide minimum radial photon flux gradient (see below, handling of error sources). The activation was conducted at $30 \mathrm{MeV}$ bremsstrahlung energy and $100 \mu \mathrm{A}$ mean electron beam current for a 1 hour exposure period.

\section{Gamma-spectroscopy}

After activation the samples were transferred into inactive counting vessels with the same geometry as that of the irradiation containers. After several cooling periods ( 1 day to 1 month) $\gamma$-ray spectra were taken using standard coaxial high-resolution spectrometers. The counting periods ranged between 10 minutes and 3 days. Low energy photon spectroscopy ${ }^{9}$ was not applied because of severe matrix absorption problems. 


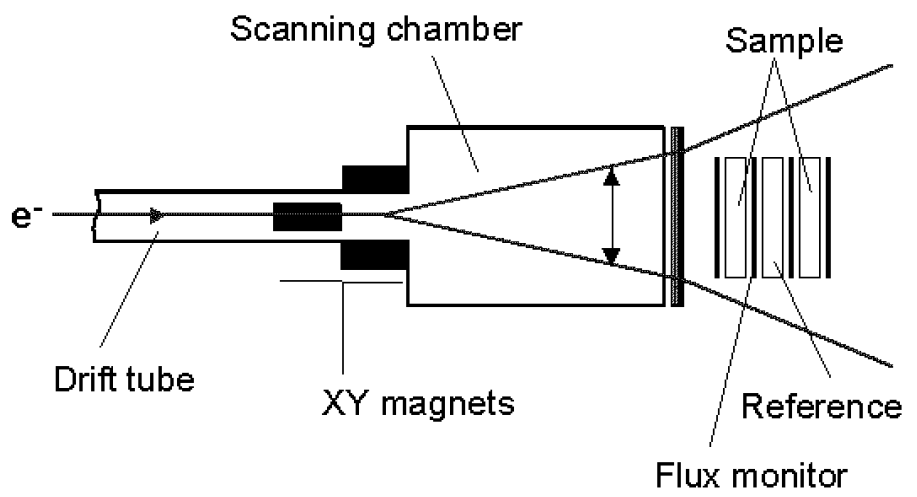

Fig. 3. Scheme of the large sample irradiation at the BAM LINAC

\section{Handling of error sources of IPAA}

Inhomogeneity of the sample: Options to tackle this problem were limited due to the extremely different sizes, densities, geometries, surface properties, etc. of the single grains in the sample. Hence, the representativeness can be influenced by selecting an adequate sample size nearly only.

Flux density gradients of the activating photon beam: The use of copper flux monitors (see above) accounts for the axial gradient. Influence of the radial gradient which appears at the borders of the scanning bremsstrahlung field is minimized by adjusting the beam scanner so that the bremsstrahlung field diameter was somewhat greater than the diameter of the sample containers (Fig. 3).

Measurement geometry: Measurement results are deteriorated by uncontrolled axial and radial shift of the sample position in front of the detector. This influence increases with decreasing distance of the sample to the detector. Therefore, the samples were measured at a distance of $12 \mathrm{~cm}$ from the front side of the detector housing. The radial shift of the radiation source cannot be controlled directly when measuring strongly inhomogeneous samples. However, this influence is also minimized by measuring at larger distance. In the future the use of a twin detector spectrometer will reduce the influence of mesurement geometry significantly (see GOERNER et al.). ${ }^{4}$

Radiation absorption: The absorption of the activating photon radiation is accounted for by using flux monitors fixed to the front and the rear surface of the irradiation vessel (see above; flux density gradient). However, the bremsstrahlung absorption is relevant only if thick items with high average atomic number are activated. This was not the case in the material studied but might gain significance when handling electronic waste which contains large amounts of heavier components, e.g., lead. In contrast, the matrix absorption of the $\gamma$-rays during spectroscopy is a greater problem. One way to minimize the deterioration of the respective results is to reduce the thickness of the sample to be measured as far as it is practicable. Furthermore, energydependent corrective absorption factors can be included in the concentration calculation. These factors can be obtained by absorption experiments using inactive samples of the material studied. ${ }^{4}$

Calibration and quality control: Waste incineration ash $^{10}$ with well-known contents of 44 elements was used for calibration in IPAA. As yet, there is no adequate material available for analytical quality control. Moreover, this also applies to the calibration material. The fly ash used in our approach was quite well usable since its attenuation behavior against the radiation involved in the analytical procedure is very similar to that of the waste material studied (similar average atomic numbers). However, this material was prepared at BAM in consideral amounts (about $5 \mathrm{~kg}$ are still available) for internal use, but is not generally available. To meet the quality requirements of respective normative documents (e.g., ISO 17025), both calibration and control material would have to be produced in considerable amounts, not to mention the certification campaigns necessary. The "classical" mode of calibration/quality control (similar amounts of sample and calibration/control material) would require excessive consumption of these materials. This would imply considerable costs, thus diminishing the economical advantage of large sample analysis. ${ }^{7}$ In INAA, the $k_{0}$ single comparator approach was applied. ${ }^{11}$ However, this is not applicable in IPAA since some of the required atomic data of the elements and several parameters of the activating photon source used (particularly linear accelerators as used in this work) cannot be defined with sufficient precision. Hence, currently in the BAM PAA laboratory feasibility studies are performed concerning the use of comparatively small masses of reference materials and extrapolation of 
the values obtained to the actual sample size. In other context, the problem of extrapolation from small to large volumes comprised by analytical techniques was discussed by GOERNER et al. ${ }^{5}$

\section{Results and discussion}

The elements detected and their photonuclear reaction data ${ }^{12}$ are compiled in Table 1 . In Table 2 the comparison of the data obtained by IPAA and INAA, respectively, is listed. The agreement of the results covers a broad range from "good" to "poor". The reason for the latter might be two-fold: (1) the IPAA results are obtained from analyses of five single $150 \mathrm{~g}$ samples whilst one single batch of $1.2 \mathrm{~kg}$ was analyzed by INAA, hence the experimental conditions were not comparable; (2) the distribution of some elements is extremely inhomogeneous so that yet larger amounts will have to be analyzed to obtain better representativeness, thus better agreement between the results of different analytical techniques.

As to the representativeness: The precision (in terms of $1 \sigma$-standard deviation based upon 5 single determinations (Tables 3-6) of the analytical results of a selected set of components as a function of the single sample mass is displayed in Fig. 4.

Table 1. Elements detected in electronic waste and photonuclear data ${ }^{12}$

\begin{tabular}{|c|c|c|c|c|}
\hline Element & Reaction & $\begin{array}{l}\text { Product } \\
\text { half-life }\end{array}$ & $\begin{array}{l}\text { Photon energies, } \\
\text { keV (intensity, \%) }\end{array}$ & $\begin{array}{c}\text { Limit of detection, }{ }^{*} \\
\mu \mathrm{g} / \mathrm{g}\end{array}$ \\
\hline Sodium & ${ }^{23} \mathrm{Na}(\gamma, \mathrm{n})^{22} \mathrm{Na}$ & $2.6 \mathrm{a}$ & $1275(100)$ & 2300 \\
\hline Calcium & ${ }^{48} \mathrm{Ca}(\gamma, \mathrm{n}){ }^{47} \mathrm{Ca}$ & $4.54 \mathrm{~d}$ & $1297(75)$ & 50 \\
\hline Titanium & ${ }^{49} \mathrm{Ti}(\gamma, \mathrm{n}){ }^{48} \mathrm{Sc}$ & $43.7 \mathrm{~h}$ & 984 (100), 1312 (100) & 45 \\
\hline Chromium & ${ }^{52} \mathrm{Cr}(\gamma, \mathrm{n}){ }^{51} \mathrm{Cr}$ & $27.7 \mathrm{~d}$ & $320(70)$ & 20 \\
\hline Manganese & ${ }^{55} \mathrm{Mn}(\gamma, \mathrm{n})^{54} \mathrm{Mn}$ & $312 \mathrm{~d}$ & $835(100)$ & 75 \\
\hline Iron & ${ }^{54} \mathrm{Fe}(\gamma, \mathrm{np})^{52} \mathrm{Mn}$ & $5.7 \mathrm{~d}$ & 744 (85), 1434 (100) & 350 \\
\hline Cobalt & ${ }^{59} \mathrm{Co}(\gamma, n){ }^{58} \mathrm{Co}$ & $70.78 \mathrm{~d}$ & $811(100)$ & 60 \\
\hline Nickel & ${ }^{58} \mathrm{Ni}(\gamma, \mathrm{n}){ }^{57} \mathrm{Ni}$ & $36 \mathrm{~h}$ & 1379 (79), $1920(15)$ & 55 \\
\hline Copper & ${ }^{65} \mathrm{Cu}(\gamma, \mathrm{n}){ }^{64} \mathrm{Cu}$ & $12.7 \mathrm{~h}$ & $1346(0.6)$ & 2000 \\
\hline Zinc & ${ }^{66} \mathrm{Zn}(\gamma, \mathrm{n})^{65} \mathrm{Zn}$ & $244 d$ & $1116(51)$ & 245 \\
\hline Arsenic & ${ }^{75} \mathrm{As}(\gamma, \mathrm{n}){ }^{74} \mathrm{As}$ & $17.8 \mathrm{~d}$ & $596(60), 635(15)$ & 80 \\
\hline Bromine & ${ }^{79} \mathrm{Br}(\gamma, 2 \mathrm{n}){ }^{77} \mathrm{Br}$ & $57 \mathrm{~h}$ & $239(22), 521(24)$ & 45 \\
\hline Rubidium & ${ }^{85} \mathrm{Rb}(\gamma, \mathrm{n}){ }^{84} \mathrm{Rb}$ & $34.5 \mathrm{~d}$ & $882(74)$ & 22 \\
\hline Strontium & ${ }^{84} \mathrm{Sr}(\gamma, \mathrm{n}){ }^{83} \mathrm{Sr}$ & $34.5 \mathrm{~d}$ & $763(30)$ & 1100 \\
\hline Yttrium & ${ }^{89} \mathrm{Y}(\gamma, \mathrm{n}){ }^{88} \mathrm{Y}$ & $107 \mathrm{~d}$ & 898 (91), 1836 (99) & 450 \\
\hline Zirconium & ${ }^{90} \mathrm{Zr}(\gamma, \mathrm{n}){ }^{89} \mathrm{Zr}$ & $78.4 \mathrm{~h}$ & 909 (99) & 15 \\
\hline Silver & ${ }^{107} \mathrm{Ag}(\gamma, \mathrm{n}){ }^{106 \mathrm{~m}} \mathrm{Ag}$ & $8.3 \mathrm{~d}$ & 451 (28), 717 (29) & 10 \\
\hline \multirow[t]{2}{*}{ Cadmium } & ${ }^{116} \mathrm{Cd}(\gamma, \mathrm{n}){ }^{115} \mathrm{Cd}$ & $53.4 \mathrm{~h}$ & $528(50)$ & 35 \\
\hline & ${ }^{115} \mathrm{Cd}(\gamma)^{115 \mathrm{~m}} \operatorname{In}$ & & $336(46)$ & \\
\hline Tin & ${ }^{112} \operatorname{Sn}(\gamma, p)^{111} \operatorname{In}$ & $2.81 \mathrm{~d}$ & 171 (89), 245 (94) & 145 \\
\hline Antimony & ${ }^{123} \mathrm{Sb}(\gamma, \mathrm{n}){ }^{122} \mathrm{Sb}$ & $2.7 \mathrm{~d}$ & $565(70), 693(4)$ & 10 \\
\hline Barium & ${ }^{136} \mathrm{Ba}(\gamma, \mathrm{n}){ }^{135 \mathrm{~m}} \mathrm{Ba}$ & $28.7 \mathrm{~h}$ & $268(16)$ & 210 \\
\hline Cerium & ${ }^{140} \mathrm{Ce}(\gamma, \mathrm{n}){ }^{139} \mathrm{Ce}$ & $137.6 \mathrm{~d}$ & $166(80)$ & 95 \\
\hline Lead & ${ }^{204} \mathrm{~Pb}(\gamma, \mathrm{n}){ }^{203} \mathrm{~Pb}$ & $51.9 \mathrm{~h}$ & $279(81), 401(4)$ & 35 \\
\hline Uranium & ${ }^{238} \mathrm{U}(\gamma, \mathrm{n}){ }^{237} \mathrm{U}$ & $6.75 \mathrm{~d}$ & $208(23)$ & 30 \\
\hline
\end{tabular}

* For a $150 \mathrm{~g}$ sample, 1-hour irradiation.

Only medium to long-lived nuclides are included. 
Table 2. Comparison of the results obtained by IPAA and INAA (in $\mu \mathrm{g} / \mathrm{g} \pm 1 \sigma$ S.D. rel. $\%$ or as indicated)

\begin{tabular}{|c|c|c|}
\hline Element & IPAA & INAA \\
\hline $\mathrm{Na}, \%$ & $4.8(16)$ & $4.6(3.0)$ \\
\hline $\mathrm{K}, \%$ & n.d. & $5.22(3.3)$ \\
\hline $\mathrm{Ca}$ & $652(6)$ & n.d. \\
\hline $\mathrm{Sc}$ & n.d. & $0.728(5)$ \\
\hline $\mathrm{Ti}$ & $183(13)$ & n.d. \\
\hline $\mathrm{Cr}$ & $31(26)$ & $48.8(9.2)$ \\
\hline $\mathrm{Mn}$ & $151(14)$ & n.d. \\
\hline $\mathrm{Fe}$ & $387(25)$ & $675(14)$ \\
\hline $\mathrm{Co}$ & n.d. & $11.5(5.5)$ \\
\hline $\mathrm{Ni}$ & $134(20)$ & n.d. \\
\hline $\mathrm{Cu}, \%$ & $4.8(9)$ & $5.36(8.3)$ \\
\hline $\mathrm{Zn}, \%$ & $0.167(16)$ & $0.162(3.8)$ \\
\hline As & n.d. & $58(22)$ \\
\hline $\mathrm{Br}$ & $689(5)$ & $719(1.4)$ \\
\hline $\mathrm{Rb}$ & $54(16)$ & $47.2(14)$ \\
\hline $\mathrm{Sr}, \%$ & 3.97 (9) & $3.55(11)$ \\
\hline $\mathrm{Y}$ & $84(13)$ & n.d. \\
\hline $\mathrm{Zr}, \%$ & $0.097(5)$ & $0.196(9.8)$ \\
\hline $\mathrm{Ag}$ & $14(28)$ & $25.7(8.4)$ \\
\hline $\mathrm{Cd}$ & $94(9.8)$ & n.d. \\
\hline $\mathrm{Sn}, \%$ & $0.127(5)$ & $0.122(35)$ \\
\hline $\mathrm{Sb}, \%$ & $0.226(8)$ & $0.247(1.1)$ \\
\hline $\mathrm{Cs}$ & n.d. & $1.69(15)$ \\
\hline $\mathrm{Ba}, \%$ & $4.15(11)$ & $4.5(2.0)$ \\
\hline $\mathrm{La}$ & n.d. & $130(3)$ \\
\hline $\mathrm{Ce}, \%$ & $0.23(16)$ & $0.218(2.8)$ \\
\hline $\mathrm{Nd}$ & n.d. & $74(18)$ \\
\hline $\mathrm{Sm}$ & n.d. & $4.07(6.1)$ \\
\hline $\mathrm{Eu}$ & n.d. & $0.41(33)$ \\
\hline $\mathrm{Yb}$ & n.d. & $1.48(32)$ \\
\hline Hf & n.d. & $52.1(3.1)$ \\
\hline $\mathrm{Au}$ & n.d. & $1.91(2.1)$ \\
\hline $\mathrm{Pb}, \%$ & 0.107 (10) & n.d. \\
\hline Th & n.d. & $10.2(6.1)$ \\
\hline $\mathrm{U}$ & $5.4(13)$ & n.d. \\
\hline
\end{tabular}

n.d.: Not determined.

Table 3. Results of $1 \mathrm{~g}$-samples (Group A) (in $\mu \mathrm{g} / \mathrm{g}$ or as indicated)

\begin{tabular}{|c|c|c|c|c|c|c|}
\hline \multirow{2}{*}{ Element } & \multicolumn{5}{|c|}{ Sample number (mass, g) } & \multirow{2}{*}{$\begin{array}{l}1 \sigma \text { S.D. } \\
( \pm \text { rel. } \%)\end{array}$} \\
\hline & $\mathrm{A} 1(1.1223)$ & $\mathrm{A} 2(1.0102)$ & A3 (0.9877) & A4 (1.0032) & A5 (0.9971) & \\
\hline $\mathrm{Na}, \%$ & n.d. & 2.1 & 6.7 & n.d. & 0.4 & $3.1(106)$ \\
\hline $\mathrm{Ca}$ & 122 & 502 & 490 & 760 & 72 & $389(74)$ \\
\hline $\mathrm{Ti}$ & n.d. & n.d. & 320 & 73 & n.d. & 196 \\
\hline $\mathrm{Cr}$ & 17 & 31 & n.d. & 101 & 97 & $62(71)$ \\
\hline $\mathrm{Mn}$ & 432 & 66 & n.d. & n.d. & 114 & $204(98)$ \\
\hline $\mathrm{Ni}$ & 22 & 141 & 198 & 15 & 44 & $84(97)$ \\
\hline $\mathrm{Cu}, \%$ & n.d. & 15.1 & 2.3 & 1.4 & 8.9 & $6.9(92)$ \\
\hline $\mathrm{Zn}, \%$ & 0.021 & 0.134 & 0.188 & 0.232 & 0.109 & $0.137(59)$ \\
\hline $\mathrm{Zr}, \%$ & 0.144 & 0.0905 & 0.079 & 0.0886 & 0.093 & $0.099(25)$ \\
\hline $\mathrm{Ag}$ & n.d. & 22 & 49 & 2 & 11 & $21(97)$ \\
\hline $\mathrm{Cd}$ & 136 & 110 & 31 & 21 & 94 & $78(64)$ \\
\hline $\mathrm{Sn}, \%$ & 0.187 & 0.112 & 0.074 & 0.201 & 0.133 & $141(37)$ \\
\hline $\mathrm{Sb}, \%$ & 0.343 & 0.135 & 0.311 & 0.281 & 0.076 & $0.229(51)$ \\
\hline $\mathrm{Ba}, \%$ & 1.88 & 3.04 & 1.67 & 1.11 & 5.43 & $1.55(70)$ \\
\hline $\mathrm{Ce}, \%$ & 0.16 & 0.24 & 0.67 & 0.09 & 0.13 & $0.26(92)$ \\
\hline $\mathrm{Pb}, \%$ & 0.089 & 0.112 & 0.216 & 0.177 & 0.099 & $0.139(40)$ \\
\hline $\mathrm{U}$ & n.d. & n.d. & 1.1 & 6.7 & 3.0 & $3.6(79)$ \\
\hline
\end{tabular}

n.d.: Not detected. 
Table 4. Results of $3 \mathrm{~g}$ - samples (Group B) (in $\mu \mathrm{g} / \mathrm{g}$ or as indicated)

\begin{tabular}{|c|c|c|c|c|c|c|}
\hline \multirow{2}{*}{ Element } & \multicolumn{5}{|c|}{ Sample number (mass, g) } & \multirow{2}{*}{ 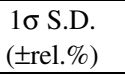 } \\
\hline & B1 (2.8711) & B2 (3.0623) & B3 (3.0012) & B4 (2.9414) & B5 (3.1120) & \\
\hline $\mathrm{Na}, \%$ & 1.1 & 4.2 & 4.9 & 1.4 & 3.2 & $3.2(57)$ \\
\hline $\mathrm{Ca}$ & 942 & 699 & 329 & 440 & 370 & $556(47)$ \\
\hline $\mathrm{Cr}$ & 59 & 72 & 29 & 18 & 40 & $101(78)$ \\
\hline $\mathrm{Mn}$ & 148 & 139 & 51 & 166 & 84 & $118(41)$ \\
\hline $\mathrm{Zn}, \%$ & 0.088 & 0.129 & 0.100 & 0.197 & 0.211 & $0.145(39)$ \\
\hline $\mathrm{Zr}, \%$ & 0.0901 & 0.083 & 0.121 & 0.0955 & 0.1003 & $0.098(15)$ \\
\hline $\mathrm{Ag}$ & n.d. & 42 & n.d. & 11 & 36 & $30(55)$ \\
\hline $\mathrm{Cd}$ & 122 & 134 & 69 & 48 & 72 & $89(42)$ \\
\hline $\mathrm{Sn}, \%$ & 0.082 & 0.110 & 0.160 & 0.100 & 0.177 & $0.126(32)$ \\
\hline $\mathrm{U}$ & 2.7 & 4.6 & 5.0 & 6.4 & 4.5 & $4.6(29)$ \\
\hline
\end{tabular}

n.d.: Not detected.

Table 5. Results of $30 \mathrm{~g}$ - samples (Group C) (in $\mu \mathrm{g} / \mathrm{g}$ or as indicated)

\begin{tabular}{|c|c|c|c|c|c|c|}
\hline \multirow{2}{*}{ Element } & \multicolumn{5}{|c|}{ Sample number (mass, g) } & \multirow{2}{*}{$\begin{array}{l}1 \sigma \text { S.D. } \\
( \pm \text { rel. } \%)\end{array}$} \\
\hline & C1 (28.92) & $\mathrm{C} 2(30.23)$ & C3 (29.46) & C4 (32.11) & C5 (31.68) & \\
\hline $\mathrm{Na}, \%$ & 3.1 & 4.2 & 3.5 & 1.9 & 3.9 & $3.3(17)$ \\
\hline $\mathrm{Ca}$ & 702 & 630 & 710 & 600 & 722 & $673(8)$ \\
\hline $\mathrm{Ti}$ & 142 & 166 & 101 & 182 & 240 & $166(31)$ \\
\hline $\mathrm{Cr}$ & 21 & 44 & 39 & 27 & 18 & $30(37)$ \\
\hline $\mathrm{Mn}$ & 142 & 222 & 230 & 169 & 244 & $201(22)$ \\
\hline $\mathrm{Ni}$ & 130 & 95 & 149 & 160 & 202 & $147(27)$ \\
\hline $\mathrm{Cu}, \%$ & 5.1 & 5.3 & 4.4 & 4.2 & 5.5 & $4.9(12)$ \\
\hline $\mathrm{Zn}, \%$ & 0.101 & 0.177 & 0.162 & 0.110 & 0.171 & $0.144(25)$ \\
\hline $\mathrm{Zr}, \%$ & 0.106 & 0.092 & 0.099 & 0.110 & 0.091 & $0.997(9)$ \\
\hline $\mathrm{Ag}$ & 29 & 36 & 14 & 17 & 33 & $26(38)$ \\
\hline $\mathrm{Cd}$ & 90 & 88 & 103 & 109 & 92 & $96(9.5)$ \\
\hline $\mathrm{Sn}, \%$ & 0.144 & 0.159 & 0.121 & 0.147 & 0.118 & $0.138(13)$ \\
\hline $\mathrm{Sb}, \%$ & 0.180 & 0.157 & 0.141 & 0.199 & 0.231 & $0.182(19)$ \\
\hline $\mathrm{Ba}, \%$ & 4.21 & 3.82 & 3.79 & 4.47 & 4.62 & $4.18(9)$ \\
\hline $\mathrm{Ce}, \%$ & 0.25 & 0.32 & 0.16 & 0.18 & 0.29 & $0.24(29)$ \\
\hline $\mathrm{Pb}, \%$ & 0.101 & 0.087 & 0.132 & 0.120 & 0.109 & $0.110(16)$ \\
\hline $\mathrm{U}$ & 5.6 & 7.0 & 4.9 & 4.1 & 5.2 & $5.4(20)$ \\
\hline
\end{tabular}

Table 6. Results of $150 \mathrm{~g}$ - samples (Group D) (in $\mu \mathrm{g} / \mathrm{g}$ or as indicated)

\begin{tabular}{|c|c|c|c|c|c|c|}
\hline \multirow{2}{*}{ Element } & \multicolumn{5}{|c|}{ Sample number (mass, g) } & \multirow{2}{*}{$\begin{array}{l}1 \sigma \text { S.D. } \\
( \pm \text { rel. } \%)\end{array}$} \\
\hline & D1 (1.1223) & D2 (1.0102) & D3 (0.9877) & D4 (1.0032) & D5 (0.9971) & \\
\hline $\mathrm{Na}, \%$ & 4.1 & 4.9 & 4.0 & 5.2 & 5.9 & $4.8(16)$ \\
\hline $\mathrm{Ca}$ & 660 & 599 & 672 & 705 & 626 & $652(6)$ \\
\hline $\mathrm{Ti}$ & 177 & 220 & 159 & 167 & 192 & $183(13)$ \\
\hline $\mathrm{Cr}$ & 32 & 40 & 29 & 21 & 55 & $31(26)$ \\
\hline $\mathrm{Mn}$ & 151 & 133 & 128 & 169 & 175 & $151(14)$ \\
\hline $\mathrm{Ni}$ & 110 & 170 & 153 & 127 & 108 & $134(20)$ \\
\hline $\mathrm{Cu}, \%$ & 4.9 & 4.6 & 5.5 & 4.3 & 4.7 & $4.8(9)$ \\
\hline $\mathrm{Zn}, \%$ & 0.189 & 0.199 & 0.134 & 0.152 & 0.160 & $0.167(16)$ \\
\hline $\mathrm{Zr}, \%$ & 0.099 & 0.090 & 0.105 & 0.100 & 0.091 & $0.097(7)$ \\
\hline $\mathrm{Ag}$ & 18 & 17 & 26 & 22 & 12 & $19(28)$ \\
\hline $\mathrm{Cd}$ & 82 & 104 & 101 & 87 & 95 & $94(9.8)$ \\
\hline $\mathrm{Sn}, \%$ & 0.132 & 0.121 & 0.134 & 0.120 & 0.129 & $0.127(5)$ \\
\hline $\mathrm{Sb}, \%$ & 0.221 & 0.196 & 0.239 & 0.233 & 0.240 & $0.226(8)$ \\
\hline $\mathrm{Ba}, \%$ & 3.99 & 4.31 & 4.09 & 4.44 & 4.51 & $4.15(11)$ \\
\hline $\mathrm{Ce}, \%$ & 0.24 & 0.26 & 0.19 & 0.20 & 0.28 & 0.23 (16) \\
\hline $\mathrm{Pb}, \%$ & 0.099 & 0.101 & 0.120 & 0.097 & 0.118 & $0.107(10)$ \\
\hline $\mathrm{U}$ & 5.9 & 6.4 & 4.8 & 4.9 & 5.1 & $5.4(13)$ \\
\hline
\end{tabular}




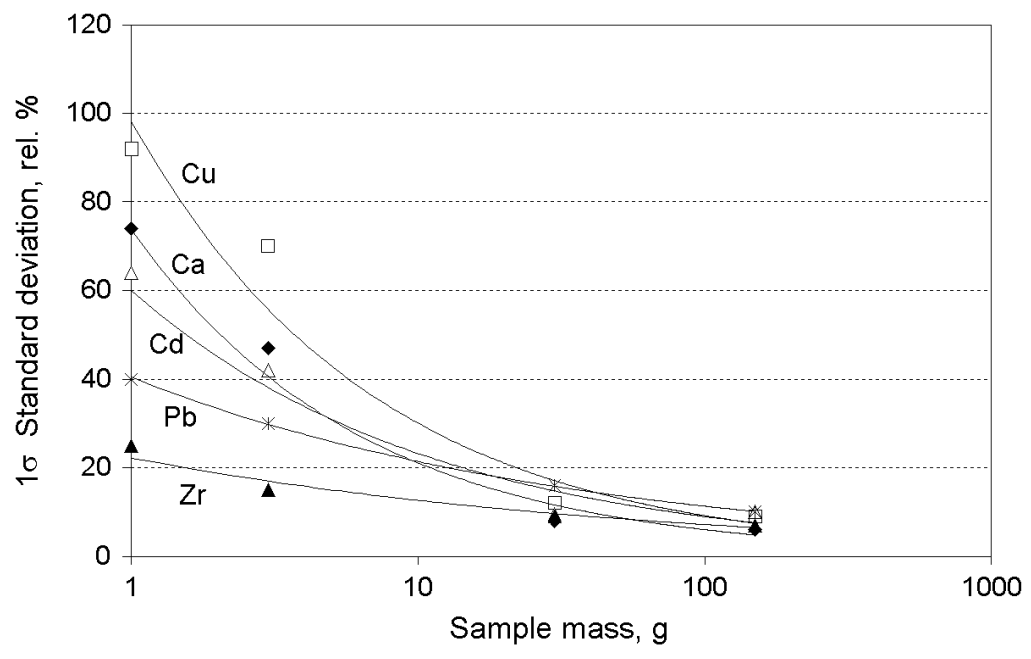

Fig. 4. Analytical uncertainty ( $1 \sigma$ standard deviation) vs. sample size function

As expected, the uncertainty of results increases dramatically with decreasing sample mass. The extremely uneven distribution of the copper values in the small samples is due to its particle properties. The major part of copper, being one of the most abundant components in the material, was present as pieces of wire, partly in coherent clusters, thus could not be distributed homogeneously. This reflects the extreme difficulty to obtain an even particle distribution, thus a representative sample from this kind of material as was pointed out by BODE et al. ${ }^{7}$ The comparatively homogeneous distribution of zirconium is due to the fact that it is component of nearly only the glass material of display screens which, being the major part of all material in the sample, lies before as small granulate, hence exhibits better homogeneity property.

The functions shown in Fig. 4 can help to find the minimum sample mass needed for the respective investigation task. In the case of electronic waste, these requirements in terms of detection limits, accuracy and precision can be different, for instance: for economical reasons, high precision is required for the analysis of valuable components like noble metals whereas the uncertainty of the other elements might be somewhat greater. However, higher precision can eventually also be required to the results of hazardous components, depending upon the actual environmental protection policy (e.g., environment-related EU Directives). Thus, requirements concerning the quality of analytical results might be strongly governed by economical/political considerations.

The mass of the sample to be analyzed has to be predefined accordingly, whatsoever.

\section{Conclusions and outlook}

Analytical procedures are described that facilitate the analysis of large amounts of materials. These techniques are helpful for characterization of inhomogeneous matter like electronic waste in particular. They can reduce costs of analyses and help to optimize recycling processes. For instance, material streams can be controlled using the analytical data quickly obtained, thus help to accelerate the recycling process and reduce energy consumption. Currently and in the future the following studies are performed and planned: to optimize the precision of $\gamma$-spectroscopy using a twin detector spectrometer; ${ }^{4}$ to proceed to yet larger sample volumes/masses; to work out photon activation analysis procedures for other materials (industrial, geological materials, other kinds of waste. etc.); to solve the problems of calibration/control materials, and to develop analytical procedures other than activation analysis for large volume investigations.

\section{References}

1. EU Directive on Waste Electrical and Electronic Equipment (WEEE), 2002/96/EC

2. EU Directive on the Restriction of the Use of Certain Hazardous Substances in Electrical and Electronic Equipment (RoHS), 2002/95/EC.

3. EU Directive on Batteries and Accumulators and Spent Batteries and Accumulators (Proposal), SEC (2003) 1343.

4. W. Goerner, D. Alber, A. Berger, O. HaAse, C. Segebade, BEAMGAA: An instrumental answer to the demand of high accuracy, in: Proc. MARC VI, 7-11 Apr. 2003, Kailua-Kona, Hawaii, USA, in print. 
5. W. Goerner, D. Alber, A. Berger, O. HaAse, M. Hedrich, N. Kardjllov, S. Merchel, M. RadtKe, H. Riesemeier, U. Reinholz, C. Segebade, J. Radioanal. Nucl. Chem., to be published.

6. O. HaAse, G. Weidemann, J. Radioanal. Nucl. Chem., to be published.

7. P. Bode, O. Lakmaker, P. VAn Aller, M. BlaAuw, Fresenius J. Anal. Chem., 360 (1998) 10.

8. R. M. W. Overwater, P. Bode, J. J. M. DE GoeiJ, J. E. Hoogenboom, Anal. Chem., 68 (1996) 341.
9. H.-P. WeISE, C. SEgEBADE, J. Radioanal. Chem. 49 (1979) 95.

10. B. F. Schmitt, C. Segebade, H.-U. Fusban, J. Radioanal. Chem., 60 (1980) 99.

11. A. Simonits, F. DE Corte, J. Hoste, J. Radioanal. Chem., 24 (1975) 31.

12. C. Segebade, H.-P. Weise, G. J. Lutz, Photon Activation Analysis, Walter de Gruyter \& Co., Berlin - New York, 1988, p. $161 \mathrm{ff}$. 